\section{Uma teoria da tecnologia}

\author{
C. Z. Mam ma na
}

\section{INTRODUÇÃO}

É com esta belíssima imagem da tecnologia que o físico-químico G. N. Lewis abre seu livro clássico de termodinâmica:

\begin{abstract}
"Há antigas catedrais que, à parte seus propósitos sagrados, inspiram solenidade e respeito. Mesmo o visitante curioso fala, dentro dela, de coisas sérias em voz baixa, e à medida que cada suspiro reverbera pela abóbada da nave, o eco que volta parece trazer uma mensagem de mistério. $O$ trabalho de gerações de arquitetos e artesãos já foi esquecido, os andaimes erguidos para os seus trabalhos há muito foram removidos, seus erros foram apagados ou ficaram escondidos pela poeira dos séculos. Olhando apenas a perfeição da obra acabada, nós nos sentimos como se diante de um agente sobre-humano. Mas algumas vezes nós entramos em um tal edifício que ainda está em construção; então o som dos martelos, o cheiro forte do tabaco, os gestos triviais trocados entre os trabalhadores nos dão a perceber que essas grandes estruturas não são senão o resultado de dar ao esforço do homem comum uma direção e um propósito"(1).
\end{abstract}

O mágico e o místico ocupam o lugar das explicações racionais sempre que o homem se vê diante do desconhecido. Os alquimistas explicavam as propriedades da matéria em termos de "espíritos ocultos"; o pensamento humano já foi imaginado como um "fluido mágico"; os mecanismos profundos e invisíveis que dão ânimo aos seres vivos apareciam aos observadores como místicos e inacessíveis. Da mesma forma, uma obra exótica e acabada, como por exemplo o robô ou o tomógrafo computadorizado dos dias de hoje, imprime no usuário inconsciente um sentimento semelhante de milagre.

Não é necessário buscarmos mais desses exemplos na antigüidade. Basta recuarmos vinte anos para constatarmos que as idéias acerca de tecnologia estão, como aquelas outras, impregnadas do misticismo dos ingênuos: hoje há uma crença generalizada de que a tecnologia é uma espécie de poção mágica que pode ser engarrafada e transportada de um lado para outro e, quando inalada por uma nação subdesenvolvida, é capaz de libertar-lhe o "espírito do desenvolvimento econômico". Alguns fenômenos econômicos ambíguos contribuíram para reforçar essa crendice. Há alguns anos, o dr. Gunnar Myrdal, prêmio Nobel de Economia, escrevia na revista Scientific American.

“(...) uns poucos países, na América Latina e no Sudeste Asiático, conseguiram quebrar as barreiras de mercado em certos campos e surgiram como exportadores de bens manufaturados. Esse é um sinal de que, em tais casos, as dificuldades da transferência de tecnologia foram superadas (...)"(2).

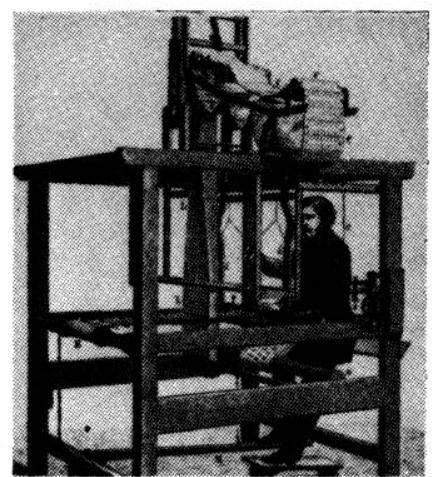

O tear revolucionário de Jacquard

C. Z. MAMMANAé professor do Instituto de Fisica da USP $\theta$ ex-presidente da ABICOMP.
1 Thermodynamics, G. N. Lewis e M. Randall. Ediçao revista e ampliada por K. S. Pitzer e L. Brewer. McGraw-Hill Book Company, Inc., 1961.

2 "The transfer of technology", G. Myrdal, in Scientific American, set./1974, p. 172.

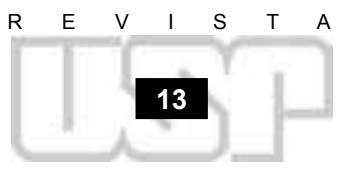


Enquanto essas crendices ocupam espaços importantes dos veículos formadores da opinião pública, observadores mais atentos constatam a reversão desse milagre: aqueles mesmos países subdesenvolvidos estão regredindo às suas velhas condições de importadores de bens manufaturados. Como um "sinal de que, em tais casos, as dificuldades da transferência de tecnologia 'não' foram superadas'...

Para a maioria da população miserável e semi-miserável dos países em desenvolvimento, a importância econômica do tema exige reflexões fundadas em bases sólidas. Ao menos mais sólidas do que simples conjeturas mistificadas, refratadas e fortalecidas por um corpo de interesses que hoje alcançaram dimensões planetárias. $O$ que se busca é uma teoria da tecnologia a partir da qual conclusões possam ser retiradas por métodos mais racionais.

\section{O QUE É TECNOLOGIA?}

A palavra tecnologia deveria designar - como na terminologia tradicional designam as palavras biologia, geologia, embriologia ou psicologia - o nome de uma ciência: a ciência que estuda a técnica. E, uma vez que técnica significa arte ou artifício, tecnologia deveria ser entendida como uma das ciências antropológicas. Hoje, em vez disso, confundimos, numa metonímia, a ciência com seu objeto de estudo - uma confusão que beneficia somente àqueles que fazem, como na Idade Média se fez com as indulgências, do místico intangível um comércio rentável. Tecnologia é tratada mais seriamente e de forma explícita como ciência, por alguns poucos antropólogos. Para V. Gordon Childe, por exemplo, "tecnologia deveria significar o estudo daquelas atividades dirigidas para a satisfação das necessidades humanas que produzem alterações no mundo material"(3).

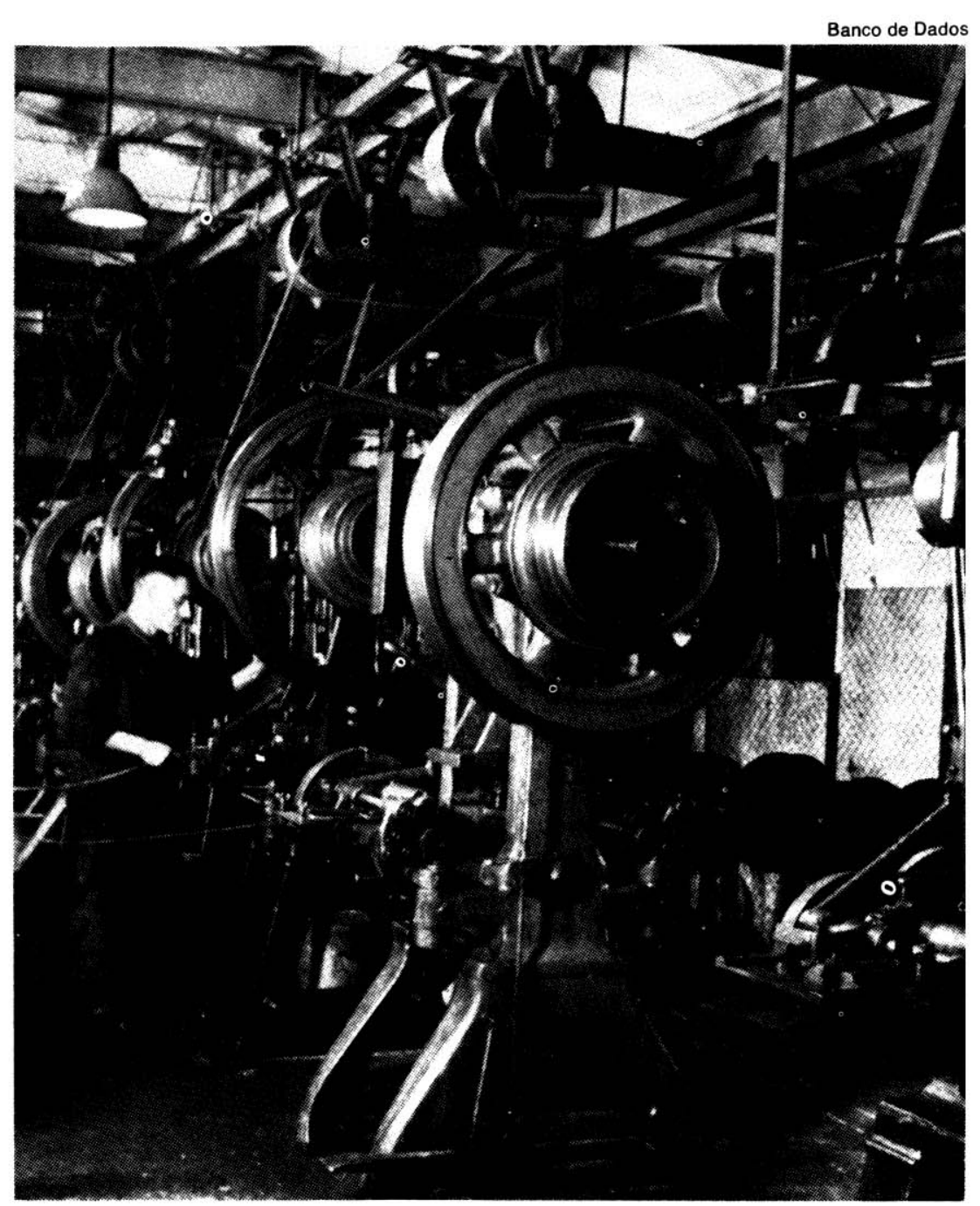

Segundo A. Leroi-Gourhan, o homem cerca-se de um invólucro artificial que o separa da natureza: ele consome sua madeira por meio da enxo; sua carne pela flecha, pela faca, a panela e a colher. $O$ estudo dessa película é a tecnologia, cujas leis do desenvolvimento dependem da economia técnica ${ }^{(4)}$.

Se tomarmos o cuidado de excluir, do escopo da definição de Childe, as atividades metabolicas humanas que nela indesejavelmente se infiltram, restam aquelas que podemos confundir com "trabalho". De fato, trabalho é usualmente entendido como a aplicação das forças e faculdades humanas para alcançar um determinado fim ou, então, como a atividade coordenada, de caráter físico ou intelectual, necessária à realização de qualquer tarefa, serviço ou empreendimento. Assim, para esses autores, tecnologia pode ser confundida com o estudo do trabalho e seus efeitos. Pode-se constatar que a tecnologia, assim entendida, vem sendo considerada como a essência dos processos econômicos desde os tempos em que os filosofos se puseram a investigar acerca da natureza e das causas da riqueza das nações.

Para Adam Smith, o primeiro dos economistas, quaisquer que sejam a qualidade do solo, do clima ou a extensão do território de uma nação, a abundância ou a carência de sua produção anual depende - mais do que de qualquer outro fator - do engenho, da destreza e do discernimento com que o trabalho é efetuado(5). Para os economistas de hoje, "a chave para o maior desempenho é

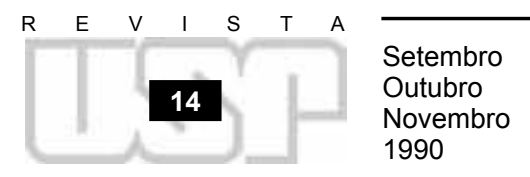


a tecnologia, que inclui não apenas novos produtos e equipamentos avançados de manufatura, mas também a eficiente organização do trabalho e o uso efetivo das pessoas"(6).

De modo a buscar uma teoria capaz de abarcar os aspectos relevantes da tecnologia, que tornassem coerentes os pontos de vista de antropólogos e economistas, eu ousei propor, há alguns anos, num pequeno ensaio ${ }^{(7)}$, algumas interpretaçōes dos fenômenos tecnológicos. O restante deste trabalho representa uma reformulação e revisão das idéias nele apresentadas.

Ao iniciar estas considerações acerca da tecnologia, cabe observar que, mais do que em qualquer disciplina do conhecimento humano, nas ciências sociais vale a máxima que figura no Curso de lingütstica geral de F. Saussure: "Bem longe de dizer que o objeto precede o ponto de vista, diríamos que é o ponto de vista que cria o objeto"(8). Sabendo desse compromisso inevitável, optei por iniciar este estudo pela tentativa de carrear para a tecnologia algumas abordagens teóricas e metodológicas bem-sucedidas em outras disciplinas das ciências antropológicas, notadamente a própria lingüística.

\section{TÉCNICA E LINGUAGEM}

Decompostas em suas unidades fisiológicas fundamentais, todas as mensagens faladas - de cujos arranjos emerge o gigantesco edifício da linguagem humana - resolvemse na articulação seqüencial de um conjunto limitado de músculos da anatomia. Por outro lado, essas mesmas mensagens, postas no papel pela habilidade técnica do calígrafo, resolvem-se na articulação seqüencial de um outro conjunto limitado de músculos dessa mesma anatomia.

Vistas do lado de fora do córtex do cérebro, pode-se afirmar que linguagem e técnica escoam de uma mesma fonte. Dela escoam não apenas o falar ou escrever à mão, mas desenhar, esculpir, empunhar uma ferramenta ou dançar. Todas são atividades que se resolvem da mesma forma: na articulação seqüencial de um determinado conjunto de músculos coordenados por um mesmo órgão.

Mais de seiscentos músculos do corpo são coordenados, em alto grau de precisão, pelo córtex cerebral. Esse gigantesco sistema combinatório confere ao ser humano uma enorme plasticidade, da qual resultam as possibilidades, virtualmente infinitas, de expressão. O mesmo conjunto de músculos da face pode configurar-se de modo a produzir expressões de dor, de angústia, de alegria, de ansiedade, de prazer ou de medo. O sistema neuro-muscular está na origem de todas as manifestaçōes culturais: a linguagem, a arte, o folclore, em suma, toda a técnica. Embora muitos antropólogos coloquem lado a lado a técnica e a linguagem dentre seus objetos de estudo, é esta última que tem merecido a maior parte das atenções. Disciplinas como a gramática, a filologia e principalmente a lingüística não têm a sua correspondente contrapartida no estudo da técnica.

\section{GRAMÁTICA DO GESTO}

Um estudo comparativo entre técnica e linguagem deveria abarcar a questão fundamental de existir ou não uma espécie de gramática das ações técnicas. Alguns esforços foram feitos na direção de se estabelecer uma gramática do gesto, especialmente na busca de um léxico de posturas e gestos capazes de orientar dançarinos e atores nas representações teatrais $^{(9)}$. Outros esforços compõem a teoria da administração científica do trabalho, conhecida por "taylorismo". Hoje em dia, esses esforços têm em vista a robótica. Robôs memorizam o movimento articulado mais ou menos como o discurso pode ser gravado em fitas magnéticas.

Embora capaz de memorizar a fala, a gravação do som não discrimina, como o faz a escrita, a natureza discreta ou os elementos articulados que fazem do discurso um objeto da gramática - os equipamentos de áudio não foram projetados para efetuar a análise léxica ou sintática dos sinais recebidos. Pesquisas nessa direção ainda estão no seu início, de modo que é possível que vejamos, num futuro próximo, o surgimento de uma teoria da sintaxe das ações técnicas.

Os algebristas demonstraram que a linguagem pode ser entendida como a articulação, transitivamente reiterada, de um conjunto elementar de fonemas. Poderíamos nos valer de uma tal imagem para interpretar a ação técnica? Parece exeqǘvel analisar os objetos técnicos como o resultado da articulação e concatenação de um número enorme de pequenas ações musculares. Essas ações podem levar à construção de uma ferramenta que, como uma memória, perpetua um conjunto determinado de ações elementares, de modo

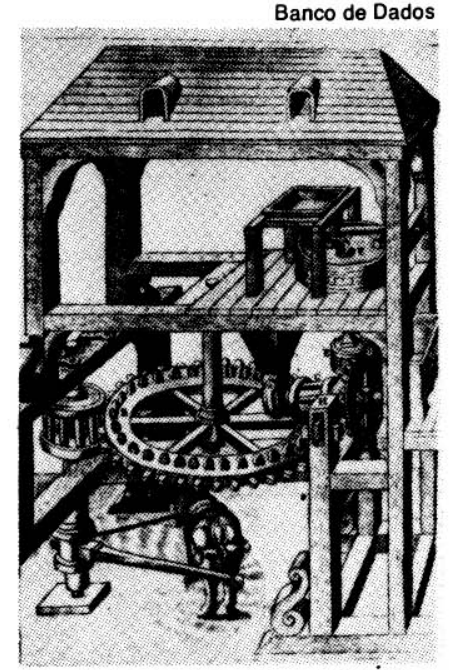

Na página ao lado, lagar movido por animais (ou homens), do século XVi; abaixo, polés e rodas transmitindo força motriz às máquinas.
3 "Early forms of society", C. Singer et alii (eds.), in History of technology vol. 1. Oxford at the Clarendon Press, 1956.

4 Evolution et Techniques vol. 2, A. Leroi-Gourhan. Milieu et Techniques. Albin Michel, 1973.

5 "An inquiry into the nature and causes of the wealth of nations", A Smith, in Enc. Brit., 1952.

6 U. S. Congress, Office of Technology Assesment, "Making things better competing in manufacture", J. H. DC - US Government Printing Office, fev./1990.

7 "A traduçăo matemática da tecnologia', C. Z. Mammana, in Dados $\theta$ İérias vol. $1, n^{2} 3$, dez./1976.

8 Curso de lingülstica geral, F. Saussure. Cultrix, 1972.

9 Every little movement - $A$ book about François Delsarte, T. Shawn. Dance Hoirons, Inc. 2nd. Printing, 1974.

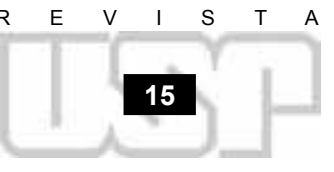


que, nas ações técnicas instrumentadas por ferramentas, estas últimas podem ser decompostas em ações técnicas elementares no seu próprio direito.

Enquanto não formos capazes de avançar nosso conhecimento acerca da gramática das ações técnicas, nós podemos aceitar a sua existência como uma hipótese de trabalho e reformular a questão do desenvolvimento tecnológico das economias em termos "lingüísticos", como veremos a seguir. A função social da linguagem é alcançada quando diferentes membros de uma sociedade forem capazes de, independente e voluntariamente, expressar-se criativamente nos processos de comunicação que têm lugar em suas vidas. A função principal da fala é a veiculação de "novas" idéias.

Economias competentes (leia-se, na terminologia de hoje em dia, competitivas) são aquelas cuja heurística e inventividade fazem parte integrante dos processos econômicos. Elas são essencialmente diferentes daquelas economias cuja capacidade está limitada a reproduzir bens manufaturados, sem o concurso da consciência ou da inventividade. Artesãos analfabetos podem ser treinados para reproduzir obras de Shakespeare ou de Einstein, talvez adicionando-lhes interessantes contribuições caligraficas; entretanto, nessa tarefa, a essência da linguagem passará por suas mãos tão imperturbavelmente quanto a água que escoa por uma tubulação. É exatamente isso o que se passa com as tecnologias "transferidas" aos países subdesenvolvidos. E aí está porque a expressão "transferência de tecnologia" deve ser considerada um abuso.

Para a tecnologia, mais importante do que o objeto é o processo que o produz. Nós sabemos que, para ter significado econômico, um processo industrial não deve ser capaz apenas de construir um artefato mas, sobretudo, de reproduzi-lo um número enorme de vezes, isto $\in$, naquelas cifras que conhecemos por escala industrial. Usando a imagem de G. N. Lewis que abriu este artigo, podemos afirmar que a essência da tecnologia está nos andaimes, não no edifício.

$\mathrm{O}$ aprendizado da linguagem pelo indivíduo é um processo complexo que consome um grande período de sua infância. Por outro lado, como nós aprendemos da lingüística, a linguagem é uma espécie de ser vivo que se transforma e evolui, numa escala coletiva, quase imperceptivelmente, através das gerações. $O$ aprendizado da técnica também ocorre em duas instâncias: a individual e a coletiva. Um processo de aprendizado coletivo que parece ser usual na história é o da imitação. $O$ que tem de ser aprendido não é a capacidade de copiar este ou aquele artefato. A imitação não é, e talvez nunca tenha sido, a atividade de um único artesão. Para ser eficaz como aprendizado, essa imitação, como veremos adiante, deve redundar num processo capaz de adicionar alguma novidade à sua coletividade. Ela deve ser um processo inteligente e criativo, algo como o que hoje se denomina "engenharia reversa". A engenharia reversa é uma espécie de arqueologia do objeto; ao praticá-la, os técnicos de hoje estão executando muito daquilo que os arqueólogos fazem por ofício: deduzir, a partir da observação de um "achado" arqueológico, os processos técnicos que o produziram. Em outras palavras, a engenharia reversa é aquela capaz de reconstruir ou simular, no seu próprio grupo étnico, a civilização "oculta" que deu origem ao objeto copiado. Novamente: o objeto tecnológico de uma cópia deve ser o andaime, não o edifício.

\section{EVOLUÇÃo DA TÉCNICA}

A lingüística abriu-nos importantes perspectivas no estudo da linguagem, em especial mostrou-nos sua dimensão evolutiva ao mesmo tempo em que nos proporcionou um paradigma evolucionista suficientemente distinto do biologico para ser aceito, pelos estudiosos das ciências sociais, com menos reservas. Com seu exemplo, torna-se mais aceitável a idéia de que vários - e não apenas um - sistemas evolutivos são imagináveis, e suas propriedades formais sistematicamente estudadas.

Para que se tenha um sistema evolutivo, duas propriedades estruturais conjugadas devem estar presentes: a estabilidade e a variabilidade. Tanto os mecanismos por meio dos quais a estabilidade é mantida, quanto as condições excepcionais em que essa estabilidade pode ser perturbada para que se dê o enriquecimento de sua variedade - e assim ele evolua -, podem variar de um sistema para outro. A estabilidade, em qualquer sistema evolutivo, pressupõe a existência de uma memória. Essa memória é facilmente percebida no caso da linguagem. A dimensão visivelmente coletiva de uma língua (nenhum ser humano consegue dominar todo seu vocabulário, nem abarcar todas as flexões possíveis de sua gramática) bem como a ponderável estabilidade que se observa nas línguas humanas (as transformações que se dão nas línguas são processos imperceptíveis 
para uma ou mais gerações) obriga-nos a postular a existência de um substrato, de natureza coletiva, capaz de preservá-la. A esse substrato, alguns autores dão o nome de memória étnica ou coletiva ${ }^{(10)}$.

Se a língua é um sistema que evolui, estabilizado por uma memória coletiva, o mesmo se dá com a têcnica. Observadas sob uma perspectiva histórica, as atividades técnicas mostram-se mergulhadas num processo evolucionário. $O$ conhecimento técnico de um determinado grupo étnico atravessa as gerações: os hábitos, conhecimentos, valores, atitudes e habilidades, de que são feitos os processos tecnológicos, têm uma significativa estabilidade.

Na memória coletiva, como ocorre também na memória psíquica dos indivíduos ou na memória genética dos seres vivos, reside o programa que condiciona os processos, sejam eles técnicos, psíquicos ou biológicos. A um observador mais superficial, a parte mais visível de uma economia ê a atividade das máquinas, equipamentos e instalaçōes. De fato, esse programa, sozinho, sem aqueles instrumentos de ação, não pode dar existência material e muito menos econômica à técnica, da mesma forma que não há pensamento sem cérebro nem germinação de semente sem energia ou alimento. Informação, sem um substrato material que a concretize, só tem existência potencial - é uma promessa à espera de quem a cumpra...

Entretanto, em oposição, toda essa infra-estrutura que representa o substrato material de uma economia não tem nenhuma vida, nenhuma conseqüência sem um programa que, através do trabalho humano, o coordene. Sem esse programa, toda base material de uma economia rapidamente se desestrutura, obsolesce e morre.

Toda a atividade tecnológica de um grupo étnico é a interação coordenada pelo trabalho entre a memória coletiva e seus instrumentos de ação. Embora seja comum chamar a Idade Média na Europa de era das trevas, é necessário ressaltar que foi nesse período precisamente que se edificou a infra-estrutura das indústrias químicas. Durante esse perfodo, os artesãos estavam fazendo muito daquele tipo de coisa que os químicos industriais fazem hoje. Os alquimistas, com seu número enorme, embora desorganizado, de experimentos, construíram os aparatos e técnicas de destilação, sublimação, lavagens, etc., com base nos quais a química científica pôde finalmente surgir ${ }^{(11)}$. Durante toda a Idade Média, a Europa esteve "memorizando" a infra-estrutura tecnológica (material e cultural) da Renascença.

A partir dessas considerações, podemos enunciar a primeira lei da tecnologia: "a intensidade e extensão das atividades tecnologicas de um grupo étnico são proporcionais à dimensão de sua infra-estrutura tecnologica, isto é, de seu universo de equipamentos, instalações, hábitos, atitudes e conhecimentos acumulados ao longo do tempo. $\mathrm{A}$ infraestrutura tecnológica é parte material e cultural do patrimônio desse grupo".

A memória coletiva dá continuidade à evolução e mostra que as raízes da tecnologia penetram remotamente na história, prolongando-se, de forma contínua, até os nossos dias. Não deve ser por mera coincidência que os países que hoje têm indústrias químicas avançadas sejam aqueles mesmos que, em suas histórias, abrigaram a alquimia.

\section{VARIABILIDADE E MEMÓRIA}

A variedade é uma condição indispensável para tornar uma sociedade maleável e capaz de adaptar-se agilmente quando submetida a forças externas que a desloquem do equilibrio. A teoria da evolução das espécies já demonstrou definitivamente o poder que a variabilidade tem de aumentar a capacidade de adaptação: é desnecessário enfatizá-lo aqui. $\mathrm{O}$ aumento da variedade associado ao processo de desenvolvimento da tecnologia foi detectado na análise da estrutura da economia norte-americana, por um estudo baseado nas matrizes de insumo-produto ${ }^{(12)}$. Por outro lado, a pobreza de variedade de grupos étnicos subdesenvolvidos pode ser catastrófica para esses grupos. Um fenômeno econômico que ocorre com muitos agricultores africanos ilustra de que forma a falta de variedade pode provocar o colapso das relações de oferta e procura:

“(...) vejamos um agricultor que produza amendoim. A terra que cultiva é considerada imprópria à produção de outro produto, senão amendoim. (...) se o preço da venda da tonelada de amendoim viesse a diminuir, a oferta de amendoim do produtor considerado diminuiria também. Ora, nada disso! Muito pelo contrário; para poder continuar obtendo a renda mínima que lhe permite alimentar a famnlia, o produtor fará tudo o que estiver a seu alcance

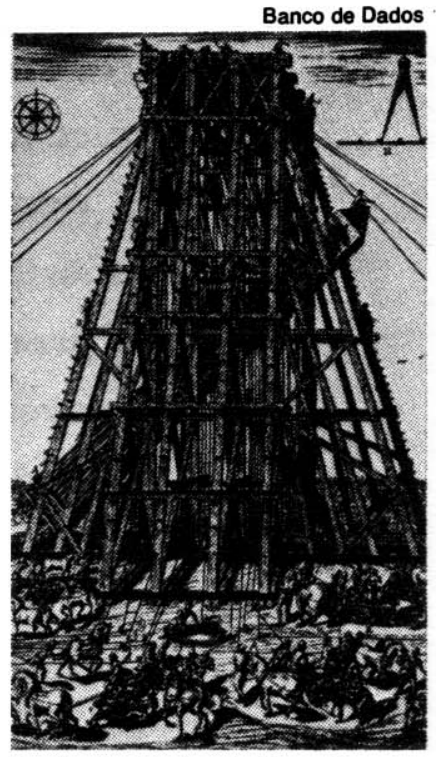

Implantação do obelisco da praça de São Pedro em Roma, 1586, que exigiu o trabalho de 300 homens e 140 cavalos 
O crescimento da variedade da

técnica num grupo étnico dá-se

por meio dos processos de

descoberta e invenção. São esses

os processos de inovação que

promovem o enriquecimento da

memória de um grupo étnico

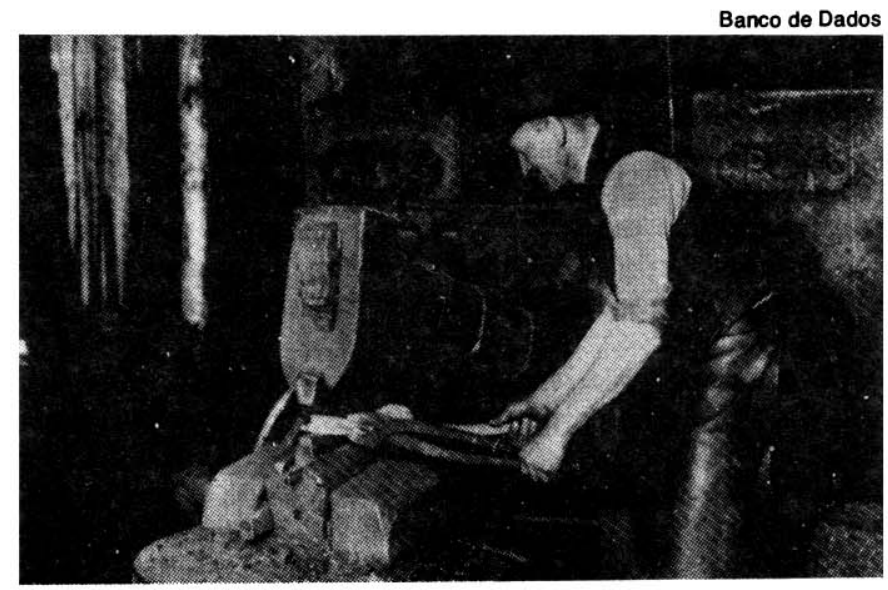

para aumentar sua produção; e este fenômeno tem qualquer coisa de dramático"(13).

A importância estratégica da técnica para um grupo étnico está fundamentalmente na variedade de opções que esse grupo tem para manipular seus recursos no atendimento de suas necessidades. A variedade armazenada na memória de um grupo étnico representa, em última análise, a capacidade desse grupo adotar, rapidamente, soluções alternativas diante de situações adversas. Podemos enunciar, então, outra lei geral da tecnologia: "o poder estratégico de um determinado grupo étnico cresce com o enriquecimento da variedade de sua técnica"

\section{Transferência de Tecnologia}

Se o processo evolutivo de um determinado grupo étnico depende do enriquecimento da variedade da sua técnica, a nova questão que se coloca é a de saber quais são os mecanismos por meio dos quais os programas técnicos são gravados em sua memória coletiva.

O entendimento da estrutura e dos princípios de funcionamento desses mecanismos é central para o avanço da presente abordagem. São muito pouco confiáveis os modelos teóricos que visam descrever sistemas dotados de memória, que são construídos apenas a partir de informações do tipo estímulo-resposta. Antes do advento da biologia molecular, que estabeleceu de forma convincente os princípios físico-químicos de funcionamento da memória genética, tanto no que diz respeito à gravação de informações como no que diz respeito à evocação, a teoria da hereditariedade esteve fundada em bases muito vulneráveis: buscavam-se leis genotípicas a partir de dados fenotípicos. Da mesma forma, enquanto a neurologia for incapaz de explicar a estrutura da memória psíquica, parte substancial do corpo de conhecimentos da psicologia continuará no ar...

Enquanto não pudermos esclarecer mais profundamente a natureza da memória coletiva, o seu substrato material e, especialmente, os princípios que regem os processos de gravação e evocação que a caracterizam, qualquer teoria que nela se baseie será conjetural: mesmo que intencionalmente se vise a essência, estar-se-á, de fato, descrevendo a aparência. Dificilmente, no seu desenvolvimento, estaremos aptos a decidir sobre a melhor analogia na comparação com outros sistemas evolutivos. Enquanto isso, devemos nos conformar com o confinamento nos limites das conjeturas mal fundadas e episodicamente verossímeis.

A. Leroi-Gourhan estabelece (ao que parece, arbitrariamente), no paralelo entre o sistema evolutivo biológico e o cultural, a analogia entre grupo étnico e espécie: "Se é exato que a espécie é a forma característica do grupamento animal e a etnia, aquela do agrupamento de homens, a cada um desses corpos de tradição deve corresponder uma forma de memória particular'(14).

Para estudarmos as interações entre diferentes grupos étnicos, deveríamos, segundo essa analogia, buscar as relações que guardam, entre si, as diferentes espécies, no que diz respeito à preservação e variação da memória genética. Na expressão de Monod, "a unidade de evolução não é qualquer população, mas sim a população que partilha de certo genoma, a saber, uma população mendeliana, com recombinação sexual conduzindo à contínua produção de novos genomas, através de recombinação"(15). 
Não estamos preparados, neste ponto, para fazer avanços nessa analogia, a ponto de identificarmos mecanismos mendelianos ou "cruzamentos" entre grupos étnicos. Porém, se nos detivermos apenas no domínio fenomenológico, constatamos que o que se observa nas interações envolvendo diferentes grupos étnicos é que, enquanto o banco de variedades acumulado nas memórias coletivas é predominantemente acessível aos indivíduos de um mesmo grupo étnico, ele é de difícil acesso a membros de outros grupos. Essa dificuldade decorre seja das diferenças culturais inerentes, seja por razões de competição entre grupos. Resulta que, como na evolução orgânica, a unidade de evolução não é o indivíduo, mas a população - o grupo étnico. Como nas espécies de seres vivos, as dificuldades de "cruzamento" entre as memórias coletivas de diferentes grupos étnicos evidencia uma espécie de blindagem a separar esses grupos.

Se essas analogias têm algum sentido, deveríamos procurar a difusão (ou transferência) de tecnologia entre dois grupos distintos, apenas naqueles processos para os quais - ocorra uma efetiva comunicação entre as memórias coletivas desses grupos e não em eventuais transações comerciais envolvendo empresas, que são unidades jurídicas mas que estão longe de ser unidades étnicas. Adicionalmente, o fortalecimento dos instrumentos jurídicos que legitimam a propriedade intelectual intensifica a blindagem natural que separa as memórias coletivas de grupos étnicos distintos.

\section{Descoberta e Invenção}

O crescimento da variedade da técnica num grupo étnico dá-se por meio dos processos de descoberta e invenção. São esses os processos de inovação que promovem o enriquecimento da memória coletiva de um determinado grupo étnico. O termo "descoberta" aplica-se, usualmente, à aquisição, por parte da comunidade, de um novo conhecimento sobre a natureza. O efeito do fogo sobre a matéria, da ampliação de forças pela alavanca, dos prismas sobre os raios luminosos, dos campos magnéticos sobre agulhas imantadas são todos exemplos de fenômenos naturais cujos entendimentos foram incorporados ao conhecimento humano, pela descoberta. A "invenção", por outro lado, consiste na aplicação de uma dada descoberta para cumprir algum fim, isto $\epsilon$, na utilização de um determinado efeito para satisfazer uma necessidade. Assim, o forno, o pé-de-cabra, as lentes, a bússola são inventos que se aproveitaram daqueles efeitos acima mencionados. Inventos mais complexos associam diversos efeitos num único mecanismo: num motor a explosão, o efeito da combustão está associado ao da expansão dos gases em um recipiente fechado que, por sua vez, está associado ao efeito da alavanca no virabrequim e assim por diante, num intrincado encadeamento. A invenção consiste, em suma, na combinação de diferentes efeitos para compor novos engenhos.

Podemos, então, imaginar que as inovações (descobertas e invenções) desempenham, numa comunidade, papel equivalente ao dos genes na hereditariedade. É a coleção dessas invenções que compõe o "genoma" da memória étnica, isto é, elas constituem a fonte de novidade e de enriquecimento de alternativas. Fica claro, pelo exposto mais atrás, que somente poderá ocorrer enriquecimento de variedade se houver um processo de gravação (incorporação), na memória coletiva, das inovações que ocorrem num determinado grupo étnico.

\section{Interdependência}

Dentre as características antropológicas da técnica, uma das mais importantes é a interdependência. $\mathrm{O}$ desenvolvimento da química, por exemplo, pode ser avaliado pelo aumento de variedades de substâncias artificiais produzidas. Hoje sabemos que o número de reações químicas possíveis está intimamente ligado às temperaturas e pressões que se consegue produzir e, por isso, a evolução da química dependeu diretamente da tecnologia dos fornos, foles e demais equipamentos industriais ou de laboratório. A possibilidade de serem usados novos reagentes e solventes nas reações químicas mostra que a evolução da química depende de seu próprio estágio de desenvolvimento.

A tecnologia do carvão influenciou um enorme número de setores tecnológicos durante os séculos XVII e XVIII, contribuindo decisivamente para a Revolução Industrial ${ }^{(16)}$; a substituição da energia animal por máquinas de potência permitiu a ampliação de muitos setores industriais que estavam limitados pela força muscular de trabalhadores e animais, e possibilitou tambem um grande aumento na variedade dos processos de conformação da materia; o aumento da variedade de ferramentas cresceu consideravelmente com a possibilidade de usinar-se o metal. Não é difícil imaginar de que forma cada um desses setores beneficiou os demais.
13 Iniciaçâo à compreensăo da economia, G. Devillebichot. Herder/Edusp. 1972.

14 Le Gest et la Parole - La Mémoire et les Rythmes, idem.

15 "A propósito da teoria molecular da evoluçăo", J. Monod, in Problemas da revoluçáo cientffica, R. Harré (org.). Edusp, 1976.

16 "The rise of coal technology", J. R. Harris, in Scientific American vol. 231, $n^{2} 2$, ago./1974. 
A dualidade fala-escrita que caracteriza as línguas das sociedades mais desenvolvidas é um exemplo visível de como dois modos de manifestação cultural originalmente independentes - a manifestação fonética e a manifestação gráfica - fundiram-se num novo todo. É lícito suspeitar que fala e escrita exerceram, ao longo da história de cada língua, fortes influências mútuas. Estudos antropológicos constataram que essa propriedade cooperativa das técnicas sempre existiu na historia e conhecem-se testemunhos de sua existência muito anteriores ao surgimento daquilo que hoje entendemos por conhecimento científico. Um elenco extenso de exemplos de cooperação de téc. nicas que precederam a denominada revolução urbana é apresentada por Childe ${ }^{(17)}$.

Com base na constatação da existência de uma propriedade cooperativa que caracteriza os feitos técnicos, pode-se inferir uma importante lei geral, que rege a dinâmica da tecnologia: "o crescimento de cada setor tecnológico é influenciado, em maior ou menor proporção, por todos os setores, inclusive por ele mesmo".

O leitor com propensões à matemática pode imaginar que, se a taxa de crescimento de cada setor é função do estágio em que se encontram todos os setores tecnológicos, então o crescimento da tecnologia pode ser descrito por um sistema de equaçōes diferenciais (ver apêndice). Esse modelo matemático, embora grosseiro, dá-nos uma idéia plausível do crescimento das técnicas: em sua evolução, alguns setores foram substituídos por outros e desapareceram; os demais sofreram um crescimento do tipo exponencial, como ocorre em geral nos sistemas cooperativos.

É necessário ressaltar que as relações de interdependência que coordenam os setores tecnológicos são estabelecidas predominantemente pela estrutura sociocultural dentro da qual esses setores existem. A análise desse modelo mostra que estruturas socioculturais diferentes levarão, inevitavelmente, a dinâmicas completamente diferentes: setores cooperativos numa estrutura podem ser competitivos em outra, pois nem tudo o que é bom para um grupo étnico, é bom para outro.

Ainda segundo esse modelo, a Revolução Industrial não teria sido um simples episódio, mas um fenômeno determinado pela própria lei da interdependência que rege o crescimento da técnica. A variação súbita no crescimento das exponenciais deixa no contemplador uma falsa impressão de descontinuidade: a sensação de salto repentino é uma espécie de ilusão dos sentidos na
Uma visão retrospectiva da Revolução Industrial, à luz da tecnologia contemporânea, nos faz interpretá-la mais como uma revolução de nałureza informática que energética: tem sido muito mais revolucionária para o sisfema produtivo a aułomação das habilidades neuronais coordenadoras (informação) do que as propulsoras (energia) 
percepção desse fenômeno na história. $O$ conhecimento cientifico também coopera, mas não em maior proporção com os demais, e é também por eles beneficiado.

Como vem sendo apontado, principalmente pelos ecologistas, a escassez de matériasprimas e a saturação do meio ambiente, inerentes a todo processo produtivo, irá impor, inevitavelmente, uma inflexão na trajetória da evolução dos setores tecnológicos. $O$ ensaio, por mim publicado em 1976, propunha que "uma análise da matriz de interdependência ilustraria como promover uma política de fomento a programas interdisciplinares visando um desenvolvimento tecnológico mais harmônico"(18).

É interessante observar que, conforme comprova o estudo de F. Kodama ${ }^{(19)}$, o governo do Japão estava promovendo, àquela época, medidas "exatamente" nessa direção. Esse mesmo estudo de Kodama enuncia o princípio da "inovação por fusão tecnológica" para explicar o sucesso do desenvolvimento tecnológico do Japão. Esse prinć́pio serve, em grande medida, como confirmação para a lei antropológica atrás enunciada.

Uma segunda reflexão revela, adicionalmente, que a matriz que deriva do modelo apresentado é uma característica do grupo étnico ao qual se refere, e representa, esquematicamente, sua estrutura sociocultural. Assim sendo, podemos concluir que a dinâmica do crescimento tecnológico é determinada substancialmente pela estrutura sociocultural daquele grupo onde se dá esse crescimento.

\section{Dessomatização}

Muitas das inovações incorporadas à memória coletiva representam a codificação de alguma habilidade humana, bem como a sua substituição por uma máquina ou ferramenta. Assim deu-se com as máquinas de tecelagem automática ou de controle de máquinas a vapor, no início da Revolução Industrial, e com os infindáveis exemplos que se acumularam neste século.

Desde o início da Revolução Industrial, as habilidades humanas vêm sendo transferidas às máquinas, num processo acelerado. Essa gradativa transferência de habilidades do homem para a máquina vem sendo perseguida deliberadamente pelos protagonistas da modernização dos processos produtivos de maneira sistemática, desde o trabalho pioneiro de Frederick $\mathrm{W}$. Taylor, The principles of scientific management, e talvez represente a verdadeira essência da Revolução Industrial. De fato, uma visão retrospectiva da Revolução Industrial, à luz da tecnologia contemporânea, nos faz interpretá-la mais como uma revolução de natureza informática do que energética: tem sido muito mais revolucionária para o sistema produtivo a automação das habilidades neuronais coordenadoras (informação) do que das propulsoras (energia).

Ao processo, por meio do qual transferem-se para a memória cultural as habilidades humanas, damos o nome de dessomatização. Usamos esse termo com o objetivo de ressaltar que esse processo representa a realização fora da "soma" (do aparelho biológico) de atividades até então realizadas exclusivamente pelo sistema nervoso humano.

Vista sob a ótica da informática, todo o processo civilizatório é marcado por eventos históricos que redundam no enriquecimento da memória cultural, freqüentemente associados a algum processo de dessomatização. Assim, podemos identificar o fenômeno do aparecimento da linguagem como aquele em que a fonética codifica uma variedade de mensagens cuja complexidade ultrapassa os limites do individual e passa a ter valor coletivo dentro de um grupo étnico; o aparecimento da escrita representa a codificação gráfica dessa fonética e induz a dessomatização da linguagem, ou, mais precisamente, de seu registro, aumentando significativamente a longevidade das mensagens; a automação da produção, intensificada ao longo da Revolução Industrial, representa a dessomatização do gesto (habilidade artesanal) e finalmente a informática moderna está promovendo a dessomatização da faculdade de processamento da informação do sistema nervoso. A esse último associa-se o processo de transformação social induzido pela invasão dos computadores na sociedade. A realização de operações aritméticas, por exemplo, efetuadas até há poucos anos quase que exclusivamente pelo homem, hoje está extensivamente automatizada. Todo o setor terciário das economias industrializadas foi impactado pelos computadores, principalmente no que diz respeito a tarefas de decisão elementar.

A cada processo de dessomatização, ocorrido na história, desencadeia-se uma profunda transformação social - normalmente um extenso processo de desapropriação ocorre. A produção e a distribuição das riquezas são profundamente influenciadas pelo grau em que se dá o processo de dessomatização das atividades informáticas. $O$ entendimento desses processos, sua natureza e seus efeitos é fundamental para compreender-

17 A evoluçăo cultural do homem, V. G. Child. Zahar, 1971.

18 Op. cit., C. Z. Mammana.

19 "Innovation throug technological fusion", F. Kodama. Conferencia profeida na USP em 10/4/85.

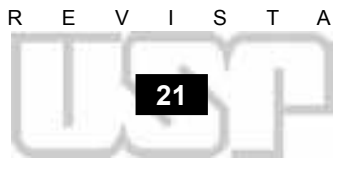


mos o impacto da informatização sobre a sociedade e sobre as possibilidades de um convívio igualitário de um povo com os demais deste planeta.

\section{CONCLUSÕES}

Neste trabalho procurei apresentar uma abordagem evolucionista (entendida sob um escopo mais abstrato do que a teoria biológica da evolução) para o estudo da tecnologia, propondo o enunciado de algumas leis antropológicas que regem o seu desenvolvimento. Elas resumem-se nas seguintes assertivas:

1) Lei da Extensividade da Tecnologia - "A intensidade e extensão das atividades tecnológicas de um grupo étnico são proporcionais à dimensão de sua infra-estrutura tecnológica, isto $\hat{E}$, de seu universo de equipamentos, hábitos, atitudes e conhecimentos acumulados ao longo do tempo. A infra-estrutura tecnológica é parte material, parte cultural do patrimônio de um grupo étnico".

2) Lei da Variabilidade - "O poder estratégico de um determinado grupo étnico cresce com o enriquecimento da variedade de sua técnica".

3) Lei da Interdependência - "O crescimento de cada setor tecnológico é influenciado, em maior ou menor proporção, por todos os setores, inclusive por ele mesmo".

Corolário: "A dinâmica do desenvolvimento tecnológico é determinado substancialmente pela estrutura sociocultural daquele grupo onde se dá esse desenvolvimento".

4) Lei da Dessomatização - "O processo civilizatório dá-se concomitantemente à progressiva dessomatização das faculdades humanas”.

Muitos dos resultados aqui apresentados dependem de conhecimentos que ultrapassam - alguns, em muito - os meus limites acadêmicos e, por essa razão, continuam válidas, como àquela época, as palavras com que introduzi o ensaio que serviu de base a este trabalho:

"Foi com o objetivo de ressaltar a natureza antropológica da tecnologia e movido mais por um sentimento de urgência do que de competência que decidi arriscar, aqui, um ensaio de teoria. Se a minha desautorizada profissão técnica obrigou-me a usar termos e conceitos que venham a chocar os antropólogos, este ensaio terá, pelo menos, o mérito de convocá-los para a discussão de um tema cuja importância para dois terços da humanidade é hoje indiscutivelmente maior do que qualquer outro de suas especialidades".

\section{APÊNDICE - A DINÂMICA DA INTERDEPENDÊNCIA}

Suponhamos que:

1) Numa economia haja " $n$ " setores tecnológicos;

2) Seus estágios de desenvolvimento possam ser medidos pelos valores das variáveis $\mathrm{X}_{1}, \mathrm{X}_{2}, \ldots, \mathrm{X}_{\mathrm{n}}$;

3) A taxa de crescimento de qualquer um deles $\left(X_{k}\right)$ seja função de todos os setores (Lei da Interdependência): $\mathrm{dX}_{\mathrm{k}} / \mathrm{dt}=\mathrm{F}_{\mathrm{k}}\left(\mathrm{X}_{1}, \mathrm{X}_{2}, \ldots, \mathrm{X}_{\mathrm{n}}\right)$.

Embora não seja possível fazer uma análise adequada de um sistema de equações diferenciais, como acima, sem conhecer as funções $F_{k}$ - principalmente se levarmos em conta que poderemos estar diante de um sistema do tipo "caótico" -, é razoável supor que durante um pequeno intervalo de tempo, significativo para os nossos fins, as variações das amplitudes das grandezas $X_{k}$ sejam pequenas o bastante para que o comportamento dessas grandezas seja determinado pela matriz jacobiana das funções $F_{k}{ }^{(20)}$, cujos elementos são: $\mathrm{a}_{\mathrm{ij}}=\mathrm{dF}_{\mathrm{i}} / \mathrm{dX}_{\mathrm{j}}$.

Cada elemento dessa matriz mostra de que forma a taxa de crescimento de um dado setor " $i$ " $\varepsilon$ influenciada pelo estágio de desenvolvimento do setor " $j$ ". Essa matriz de interdependência guarda uma certa semelhança com a matriz de insumos-produtos de Leontief (21). Salvo casos particulares da matriz $\left(a_{i j}\right)$, a solução geral desse sistema de equações, para períodos pequenos de tempo, é do tipo exponencial. Se utilizarmos uma qualquer das soluções $\mathrm{X}_{\mathrm{m}}$ do sistema de equações $\mathrm{e}$, por meio dela, eliminarmos o tempo das outras soluções, seremos levados, enganosamente, à idéia de que todos os seto-

21 "Structure of world economy - Outline of a simple input-output formulation". $W$. Leontief, in Proc of the IEEE vol. $63, n^{\circ} 3$, março/1975. res tecnológicos dependem daquele escolhido $X_{\mathrm{m}}$. Parece que é num equívoco dessa natureza que têm incorrido aqueles que imaginam a ciência como a causa do desenvolvimento tecnológico.

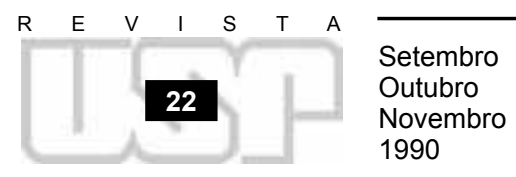

